\title{
The effect of $\beta$-adrenoreceptive antagonists on the morbidity and mortality in cardiovascular disease
}

\author{
J. D. FitzGerald \\ M.B., B.Sc., F.R.C.P.(E.) \\ McMaster University Medical Center, 1200 Main Street West, Hamilton, Ontario, Canada
}

\begin{abstract}
Summary
The effect is critically reviewed of chronic administration of $\beta$-adrenoreceptor antagonists on morbidity and mortality in angina pectoris and myocardial infarction. There is inconclusive evidence that the abrupt cessation of therapy with these agents may increase morbidity and mortality in angina pectoris. The type of anginal patient in which this may occur is not yet defined and neither is the mechanism. There is no evidence that $\beta$-antagonists prolong the life of anginal patients. In the acute phase of experimental myocardial infarction, these drugs reduce mortality but do not do so in man. There is increasing evidence that they prolong life if administered to patients surviving the acute phase of myocardial infarction. The need for further studies is discussed.
\end{abstract}

\section{Introduction}

Elevated concentrations of plasma or urinary catecholamines are frequently observed in acute myocardial infarction (Valori, Thomas and Shillingford, 1967; Jequier and Perret, 1970) and a correlation has been demonstrated between the severity of the myocardial infarction and the degree of elevation of plasma catecholamines (Griffiths and Leung, 1971). Angina pectoris (Gazes, Richardson and Woods, 1959; Raab, 1962) and essential hypertension (De Quattro, 1972) are also associated with evidence of increased catecholamine levels. These observations suggest that these common cardiovascular conditions may be accompanied at times by increased activity of sympathetic division of the autonomic system. An increased catecholamine drive to the cardiovascular system may result in tachycardia, increased ventricular contractility and a rise in cardiac output because of stimulation of cardiac $\beta$-adrenoreceptors. These changes may be accompanied by a rise in blood pressure due to stimulation of vascular $\alpha$-adrenoreceptors. The net effect of such alterations may be beneficial or harmful in accordance with the underlying competence of the cardiovascular system. In the presence of myocardial damage and impaired coronary perfusion, enhanced catecholamine activity may increase myocardial hypoxia leading to further impairment of function. Furthermore, enhanced sympatho-adrenal activity can lead to serious cardiac dysrhythmias particularly if the myocardium is already ischaemic (Fitzgerald, 1972).

The development of $\beta$-adrenoreceptive antagonists has provided a new type of tool to investigate the role of the sympathetic system in cardiovascular disease. Since $\beta$-antagonists are, by definition, specific antagonists of the $\beta$-adrenoreceptor (Barrett and Fitzgerald, 1968), it should be possible to delineate the conditions under which sympathetic activity is appropriate in cardiovascular disease and also where it is inappropriate. For example, there is convincing evidence from animal experiments to indicate that sympathetic activity favours the developement of serious arrhythmias in the presences of acute myocardial ischaemia (Ebert, Allgood and Sabiston, 1968; Schaal, Wallace and Sealy, 1969) The purpose of this paper is to review those studies in which $\beta$-antagonists have been administered chronically to patients with various cardiovascular disorders in order to determine whether, in the longterm, this class of drug is beneficial or harmful.

\section{Definitions}

Before examining the evidence concerning the effect of $\beta$-adrenoreceptive antagonists on morbidity and mortality these terms will be defined. Mortality is defined as the number of deaths occurring in a given period from a particular disease. It may be stratified into causes related to the disease state under consideration and those deaths due to unrelated conditions. The definition of morbidity is less precise. Certain epidemiologists consider it to be synonymous with sickness and illness. In the present review the term morbidity is used in the sense of incidence of pathological events not leading to death. Evidence relating to the incidence of symptomatic and functional morbidity is disregarded.

\section{Indications for $\beta$-antagonists}

The cardiovascular disorders in which $\beta$-antagonists may be of value are listed in Table 1 . There is no evidence that these agents alter morbidity, as defined, or mortality in phaeochromocytoma, 
TABLE 1. Cardiovascular indications for use of $\beta$-antagonists

Angina pectoris

Cardiac arrhythmias

Essential hypertension

Hypertrophic obstructive

cardiomyopathy
Fallot's tetralogy, thyrotoxicosis, hypertension or hypertrophic obstructive cardiomyopathy. The only conditions that will be discussed further will be various forms of ischaemic heart disease.

\section{$\beta$-antagonists and increased morbidity and mortality}

Although $\beta$-antagonists are characterized by possessing specific pharmacological properties whose effect should be predictable, there is no doubt that the inappropriate use of these agents has been responsible for a small but significant morbidity and mortality. Cardiovascular morbidity due to administration of $\beta$-antagonists may be: (a) heart failure, which can vary from mild impairment of ventricular function to acute pulmonary oedema; (b) conduction disturbances; (c) bradycardia, with or without systemic hypotension. These unwanted effects are more commonly observed following acute intravenous administration particularly in the setting of acute myocardial infarction. Their true incidence is impossible to determine but a survey of the literature over the past 10 years suggests that their incidence is less than $1 \%$ of all patients receiving $\beta$ antagonists. The administration of $\beta$-antagonists may also be associated with bronchospasm, exacerbation of any hypoglycaemic tendency, as well as gastrointestinal and central nervous system disturbances of a non-specific nature. A major concern at present is the oculo-cutaneous syndrome associated with the administration of practolol. Whilst the incidence of this is low the morbidity when it occurs is serious and can lead to death (Raftery and Denman, 1973; Bendtzen and Soborg, 1975; Felix, Ive and Dahl, 1975; Editorial, 1975).

More recently, attention has been drawn to the possibility that sudden withdrawal of $\beta$-antagonists in patients suffering from ischaemic heart disease may precipitate either unstable angina or acute myocardial infarction. This latter possibility was first suggested by Slome (1973) and then by Nellen (1973). They observed that whilst treating anginal patients, the abrupt withdrawal of propranolol was associated with the onset of acute myocardial infarction. This problem has subsequently been studied and reported by three groups of investigators. Alderman et al. (1974) have reported on six cases of unstable angina observed within a period of 1 year in patients from whom propranolol was abruptly withdrawn. Three of these patients developed myocardial infarc- tion and a fourth one died suddenly. In none of these cases was propranolol re-started. The authors are careful to distinguish between the return of symptoms to the pre-treatment level which might be anticipated following the withdrawal of propranolol and the much more aggressive symptoms of rest angina and marked increase in the severity of pain that their particular subjects experienced. Mizgala and Counsell (1974) have observed thirteen acute coronary events in eleven patients. These events occurred within 14 days of stopping the propranolol. Nine of their patients developed acute coronary insufficiency, four developed acute myocardial infarction and two died. Both these reports are difficult to evaluate in that there is no indication as to the total population of anginal patients who were receiving propranolol for some idea of the incidence of this complication following withdrawal of propranolol to be determined.

Olson et al. (1975) have recently reported the results of a double-blind prospective study in which propranolol was administered in a daily dose of $160-320 \mathrm{mg}$ to twenty severe anginal patients. In this prospective study the protocol demanded the substitution of placebo for propranolol. Within 2 weeks of the abrupt withdrawal of propranolol and substitution of placebo, anginal pain increased and this was accompanied by an increase in trinitrin consumption. Three of the twenty patients developed unstable angina, necessitating admission to hospital. In addition, three other patients developed complications, namely ventricular tachycardia, myocardial infarction and one sudden death. These reports raise certain problems in relationship to the use of $\beta$ antagonists in angina pectoris. First of all, there are over twenty published controlled studies of the use of $\beta$-antagonists in angina pectoris which have necessitated the abrupt transfer of patients from the active to placebo material. In only one of these studies was there a reported increase in rest pain in changing the patient from the active material to placebo. This was the report by Wilson et al. (1969) in which the effects of oxprenolol were compared with placebo in twenty patients. Six of the patients had to be withdrawn from the study since they developed status anginosus when placebo was substituted for oxprenolol. Since it is highly probable that a large number of anginal patients have had propranolol stopped abruptly in the past and have not developed any complications, there is a need to determine the type of patient who may develop this syndrome. Furthermore, if the sub-group of anginal patients who are prone to develop myocardial infarction following the abrupt withdrawal of propranolol can be defined, then studies are required to determine the mechanism of infarction induced by acute withdrawal. The complexity of the situation is emphasized 
TABLE 2. Exacerbation of ischaemia on withdrawal of $\beta$-antagonists (propranolol)

\begin{tabular}{|c|c|c|c|c|c|c|}
\hline Author & Dose & $\begin{array}{l}\text { Observation } \\
\text { period }\end{array}$ & $\begin{array}{l}\text { Number of } \\
\text { patients }\end{array}$ & Morbid events & & Comments \\
\hline Olson et al. (1975) & $160-320 \mathrm{mg}$ & 10 weeks & 20 & $\begin{array}{l}\text { Unstable angina } \\
\text { Ventricular tachycardia } \\
\text { Myocardial infarction } \\
\text { Sudden death }\end{array}$ & $\begin{array}{l}3 \\
1 \\
1 \\
1\end{array}$ & Prospective \\
\hline Mizgala et al. (1974) & $\begin{array}{l}80-400 \mathrm{mg} \\
\text { daily }\end{array}$ & $\begin{array}{l}1 \text { week- } \\
6 \text { years }\end{array}$ & 11 & $\begin{array}{l}\text { Myocardial infarction } \\
\text { Coronary insufficiency } \\
\text { Death }\end{array}$ & $\begin{array}{l}4 \\
9 \\
2\end{array}$ & $\begin{array}{l}\text { Retrospective } \\
\text { Case reports only }\end{array}$ \\
\hline Alderman et al. (1974) & $\begin{array}{l}160 \mathrm{mg} \\
\text { daily }\end{array}$ & 1 year & 6 & $\begin{array}{l}\text { Myocardial infarction } \\
\text { Sudden death }\end{array}$ & $\begin{array}{l}3 \\
1\end{array}$ & $\begin{array}{l}\text { Retrospective } \\
\text { Case reports only }\end{array}$ \\
\hline
\end{tabular}

by the recent report of Fox et al. (1975) who carried out a prospective study of the effect of $\beta$-antagonists in patients admitted to a coronary care unit because of prolonged ischaemic myocardial pain. On admission these patients, who had been receiving $\beta$ antagonists for at least 1 month previously, had their therapy abruptly stopped. Despite this there was no increase in the incidence of myocardial infarction and the authors claim a possible decrease (see below).

At the present time one may tentatively conclude that there is a risk when propranolol is stopped abruptly in a certain number of patients suffering from angina pectoris. It would seem prudent to reduce the dose of propranolol gradually if this is indicated for such things as elective angiography or surgery. There is no evidence as to what the optimal withdrawal period is. Furthermore, it appears, from some recent reports by Mizgala et al. (1974), that the gradual worsening of anginal pain whilst receiving propranolol is not necessarily an indication for its withdrawal.

\section{$\beta$-antagonists and reduced morbidity and mortality}

In reviewing the evidence that $\beta$-antagonists may be of benefit in ischaemic heart disease the studies have been classified into (a) angina pectoris, (b) myocardial infarction, and (c) sudden death. It is generally agreed that these are related but separate sections of the ischaemic heart disease spectrum. Conclusions drawn from the studies reported may have far reaching consequences on everyday practice. It is, therefore, of importance to establish the acceptable criteria of the design of such studies since this will determine whether the conclusions are warranted. In order to be acceptable, the experimental design should meet as many as possible of the performance criteria listed in Table 3 modified from Gifford and Feinstein (1969). These authors reviewed the methodology employed in studies of the effect of anti-coagulant therapy in acute myocardial infarction.

As a general principle, studies designed to deter- mine the effect of an intervention on morbidity and mortality should be specifically planned to answer definite questions so that the study is a true experi- $N$ mental trial rather than a survey. In a survey, data are obtained by examination of patient records, but + the treatment is left to the discretion of each indivi- 그 dual physician. In order that data are comparable, it $\circ$ is essential that a pre-planned experimental trial is ${ }^{-}$ carried out rather than a survey. The trial plan should ${ }_{\square}^{-}$ contain a clear statement as to the objectives of the study, an accurate description of the treatment to be evaluated and an account of the measurement to $5 e$ employed as well as the methods of statistical ${ }^{\mathbb{D}}$ analysis. The study should contain sufficient detail ${ }_{0} 00$ enable it to be repeated by other investigators. THe्न study should be prospective rather than retrospective in nature since retrospective studies are nearly오 always lacking in precision and completeness of data as well as containing possible bias in the selection of treatment of patients. Therapy should be randomly을 allocated on a double-blind basis and should be con- current in time as well as containing equal co-o을 interventions. Thus, unless the patients are allocated randomly to their respective treatments, there is a danger of bias which may influence which treatment the patient receives. Similar considerations apply to윽 the need for a double-blind design. In regard to simultaneous co-intervention and concurrent con- 3 trols, it is essential that the patients in both the trea-i ted and untreated groups receive the identical 3 amount of care and attention and that the treatment

TABLE 3. Trial design characteristics (based on Gifford and Feinstein, 1969)

(A) Prospective
(B) Concurrent controls
(C) Co-intervention
(D) Double-blind
(E) Random allocation
(F) Prognostic stratification
(G) Criteria for inclusion and exclusion
(H) Defined end-points
(I) Compliance and adverse effects


is given to the whole group at the same time. If not, then changes in general medical practice may influence the outcome of the study quite independently of the specific intervention.

Of crucial importance to the validity of the clinical trial is the clear definition of criteria for the inclusion and exclusion of patients. The eligible population is first defined and then those that need to be excluded are deleted from the trial. Subsequently the treatment is randomized between the two groups. Many studies randomize the patients before exclusion and this is a serious disadvantage in trial design. In regard to studies of the effects of intervention in ischaemic heart disease, it is essential that clear criteria are laid down as to the diagnosis of either myocardial infarction, angina pectoris and even sudden death. Furthermore, it is necessary to define the end-point of the study before initiating the study. In the context of ischaemic heart disease, the end-points may be fatal and non-fatal and the nonfatal events should be appropriately defined.

In the statistical analysis of the results, it is necessary to establish the comparability of the groups particularly if there is incomplete follow-up of the subjects in the study. Meticulous attention should be paid to the fate of drop-outs and the effect of dropouts on the statistical analysis should be described. Finally, if the results of the study are to be properly interpreted, it is necessary to determine the degree of patient compliance with drug therapy. Obviously the dose of drug administered should be stated and the methods used to assess compliance stated.

Whilst these design criteria may seem unnecessarily stringent, it is quite clear from the review of Gifford and Feinstein (1969) that much of the ensuing confusion concerning the value of anticoagulant therapy in acute myocardial infarction has arisen from a neglect of basic principles in trial design.

\section{Angina pectoris}

Studies of the long-term effect of adrenoreceptive blockade by propranolol in angina pectoris were first reported by Amsterdam, Wolfson and Gorlin (1968). In this study, of a total of 121 patients, the effect of propranolol (forty-three patients) and non- $\beta$-blocking medical treatment (forty-six patients) was compared with internal mammary artery implantation. The study was of 18 months' duration and the endpoint was death. There was a $5.7 \%$ mortality in the propranolol-treated group and a $14.5 \%$ mortality in the medical control group. The design weaknesses in this study are, firstly, that there was no co-intervention, namely placebo therapy, and secondly, therapy was not randomly allocated between the groups. In addition, it was an open design. In another report from the U.S.A. (Warren, Brewer and Orgain, 1974), sixty-three angina! patients were treated with propranolol and observed over 6-8 years. This study cannot be considered as a morbidity or mortality study. However, the authors in a recent abstract imply that anginal patients who obtain a $50 \%$ reduction in pain incidence whilst receiving propranolol may live longer. This study fails to meet many of the required design features for a morbidity and mortality study and the conclusion stated cannot be justified. More recently, a prospective study of the effect of propranolol in unstable angina was reported from Canada (Mitzgala et al., 1974). This report concerns sixty-eight patients suffering from unstable angina pectoris who were randomly allocated to either propranolol or placebo in addition to their other required therapy. They were observed for a mean period of 19 months and the end-points were either (a) myocardial infarction, (b) acute coronary insufficiency or (c) death. The thirty-five patients receiving placebo therapy experienced twelve coronary events and two deaths. Those anginal subjects receiving propranolol experienced five coronary events and no deaths. If the deaths and coronary events are pooled, then it is claimed that the differences between the groups are statistically significant. This well designed study would indicate that further work needs to be done in order to confirm the role of $\beta$-antagonists in this form of angina pectoris.

The most extensive study in the U.K. of the effects of $\beta$-antagonists on morbidity and mortality in angina pectoris have been reported by Lambert (1972). In his initial study reported in 1972, there were 234 anginal patients in his general practice and, of these, 117 were receiving propranolol or other $\beta$ antagonists. He noted a reduction of fatal myocardial infarction from an incidence of twenty-one in the control non- $\beta$-blocking group to three in the $\beta$ blocking treated group. As he pointed out, this was not a clinical trial but was more of a survey. The results were sufficiently encouraging to warrant a prospective study. Lambert has been carrying out such a study for the past 3 years and has kindly given access to his most recent analysis (personal communication). The present study involves a total of 316 anginal patients of whom 125 are receiving $\beta$ antagonists and 191 non- $\beta$-antagonist therapy. The study design is an open one in comparison with other therapy and is not randomized. The groups are not balanced in terms of risk factors such as smoking, family history or additional therapy. In the patients suffering from angina pectoris alone, there was a statistically significant reduction in mortality from twenty-seven in the control group to six in the $\beta$-antagonist-treated group (Table 4). The calculated percentage annual death rate was $9.5 \%$ for the non$\beta$-blocking group and only $2.5 \%$ for the $\beta$-blocking group. In addition, the annual infarct rate was reduced to $19 \%$ in the non- $\beta$-blocking group and to $5 \%$ 
TABLE 4. $\beta$-Antagonists in angina pectoris

\begin{tabular}{|c|c|c|c|c|c|c|c|}
\hline \multirow[b]{2}{*}{ Author } & \multirow{2}{*}{$\begin{array}{l}\text { No. of } \\
\text { Patients }\end{array}$} & \multirow[b]{2}{*}{ Design } & \multicolumn{2}{|c|}{ Mortality } & \multicolumn{2}{|c|}{ Morbidity } & \multirow[b]{2}{*}{ Comments } \\
\hline & & & Treated & Control & Treated & Control & \\
\hline Amsterdam et al. (1968) & $\begin{array}{l}121 \\
43 \text { treated } \\
46 \text { control }\end{array}$ & $\begin{array}{c}\text { Open } v \text {. } \\
\text { other } \\
\text { therapy }\end{array}$ & $5 \cdot 7 \%$ & $14.5 \%$ & 一 & - & $\begin{array}{l}\text { Open study, no } \\
\text { co-intervention or } \\
\text { randomization }\end{array}$ \\
\hline Davies et al. (1975) & $\begin{array}{l}35 \text { treated } \\
33 \text { control }\end{array}$ & Blind & 0 & 2 & 5 & 12 & $\begin{array}{l}\text { Good design. Unstable } \\
\text { angina only }\end{array}$ \\
\hline Lambert (1972) & 117 & $\begin{array}{l}\text { Open } v . \\
\text { other } \\
\text { therapy }\end{array}$ & 3 & 21 & 一 & - & $\begin{array}{l}\text { Open study, not } \\
\text { randomized, } \\
\text { retrospective }\end{array}$ \\
\hline Lambert (1974) & 125 & $\begin{array}{l}\text { Open } v . \\
\text { other } \\
\text { therapy }\end{array}$ & 6 & 27 & 14 & 55 & $\begin{array}{l}\text { Not randomized or } \\
\text { blind. Not balanced for } \\
\text { smoking, lipids, family } \\
\text { history or therapy }\end{array}$ \\
\hline
\end{tabular}

in the $\beta$-blocking group. On the other hand, patients receiving therapy who have had a previous myocardial infarction were not influenced either in terms of mortality or morbidity. This study suggests that propranolol reduces mortality in patients suffering from angina pectoris. However, the results must be interpreted with caution, for even though it is a prospective study, the important elements of randomization, co-intervention and double blindness are missing. In addition, not only are the groups unmatched for other coronary risk factors, but the numbers in the groups are unequal. At present this study can only be regarded as providing suggestive evidence that $\beta$-antagonists prolong life expectancy in angina pectoris.

Aronow and Stemmer (1974) have recently reported a prospective comparison of medical and surgical treatment of angina pectoris. This study involved forty anginal subjects, all of grade 3 severity. The patients were matched for risk factors, myocardial function, extent of coronary artery vessel involvement and were followed up for 12 months. Of twenty patients in the surgically treated group, one died; and of twenty patients in the medically treated group, one died. This study is lacking in performance since, although it is prospective, the numbers are too low, the patients were not randomly allocated to therapy, neither was co-intervention practised. In addition, the period of follow-up is very short. It is interesting to note that the authors previously published a study indicating that propranolol was no more effective than placebo in the treatment of angina pectoris yet all their subjects were receiving propranolol before entry to the study (Aronow, 1969).

\section{Myocardial infarction}

The first $\beta$-antagonist to be studied for its possible effects in coronary artery disease was pronetholol. Black (1967) who discovered pronetholol wrote 'the possibility that the treatment of patients. with myocardial ischaemia, with or without actual $\searrow$ infarction, with adrenergic $\beta$-receptor antagonists 0 might prolong their lives was part of our speculations about the therapeutic use of these drugs'. It is $\vec{\square}$ now 15 years since $\beta$-antagonists were first intro- $\mathbb{D}$ duced into clinical medicine and it would be appro- $\frac{\mathbb{D}}{3}$ priate if we had an answer for Black's origina speculation.

\section{Animal studies}

Studies of the effects of $\beta$-antagonists in anima. subjected to experimental myocardial infarction suggests that $\beta$-antagonists may increase survival. Morris et al. (1967) reported a prolongation of survival in conscious pigs in whom coronary flow was $\frac{\circ}{\varnothing}$

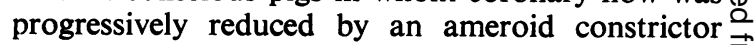
placed around the coronary artery. Survival time was $\overrightarrow{\overrightarrow{0}}$ increased from $28 \mathrm{hr}$ in the control group to $49 \mathrm{hr}$ in the group treated with i.v. propranolol $(0 \cdot 2 \mathrm{mg} / \mathrm{kg}$ 㸓 body-weight). A more comprehensive study is that by Khan, Hamilton and Manning (1972) from London, Canada, who examined the effects of propranolol, practolol and sotolol on the incidence of 3 arrhythmias and survival in conscious dogs undergoing acute ligation of the circumflex branch of the left coronary artery (Table 5). In the saline-treated control group there was an $84 \%$ mortality which was reduced to $28 \%$ by propranolol $(0.1 \mathrm{mg} / \mathrm{kg}$ i.v. $)$, $\frac{7}{0}$ to $16 \%$ by sotolol $(2 \cdot 3 \mathrm{mg} / \mathrm{kg})$ and $37 \%$ by practolol $(1.4 \mathrm{mg} / \mathrm{kg})$. Paradoxically, propranolol $(1.0 \mathrm{mg} / \mathrm{kg})$ o had no effect on survival time and neither did the $N$ D-isomer for propranolol. Sotolol, practolol, and N the high and low doses of propranolol all reduced the total number of ectopic beats and the incidence of ventricular tachycardia (Kahn et al., 1973). The authors conclude that $\beta$-antagonists significantly $\stackrel{\mathscr{\Phi}}{+}$ reduce the mortality associated with acute myo- $\stackrel{+}{-}$ cardial ischaemia in conscious dogs. The effects 
TABLE 5. $\beta$-Blockade and mortality in experimental infarction (conscious animals)

\begin{tabular}{ccccc}
\hline Author & Species & Drug & Dose $(\mathrm{mg} / \mathrm{kg})$ & Mortality (\%) \\
\hline Khan et al. (1972) & Dog & Saline & - & 84 \\
& & Propranolol & $0 \cdot 1$ & 28 \\
& & Dexpropranol & $0 \cdot 0$ & 80 \\
& & Sotalol & $3 \cdot 2$ & $68 \cdot 8$ \\
& & Practolol & $1 \cdot 4$ & $16 \cdot 7$ \\
Morris (1967) & Pig & Propranolol & $0 \cdot 2$ & $37 \cdot 5$ \\
\hline
\end{tabular}

of $\beta$-antagonists on the incidence of arrhythmias and survival following acute ligation of the left anterior descending coronary artery in anaesthetized dogs have been reported from several centres. Hope et al. (1974) examined the effects of propranolol $(1.0-1.5 \mathrm{mg} / \mathrm{kg}$ i.v.) on conduction and arrhythmias in anaesthetized dogs following ligation of the descending coronary artery. Propranolol significantly reduced the time to ventricular tachycardia but only if the heart rate itself was allowed to fall. When the heart rate was maintained by pacing at controlled levels, they could show no effect on the incidence of ventricular tachycardia. These authors suggest that the results of Khan et al. can be explained by the negative chronotropic action of propranolol. However, there was an even greater slowing of heart rate in the group of dogs receiving the high dose of propranolol in the study by Khan yet there was no increase in survival. Harris et al. (1971) have shown that practolol reduced the incidence of ventricular fibrillation and prolonged survival followed acute ligation of the coronary artery in dogs. The influence was only on the initial arrhythmias that occur in the first $\mathbf{2 0}$ min following ligation (Phase I). Pentecost (1966), using a similar model, showed that propranolol $(0.08 \mathrm{mg} / \mathrm{kg}$ i.v. $)$ prolonged survival but a dose of $0.2 \mathrm{mg} / \mathrm{kg}$ did not. The dose-dependent aspects of the action of propranolol in these experiments need further study. Kaumann and Aramendia (1968) have shown that sotolol $(10 \mathrm{mg} / \mathrm{kg}$ i.v.) prolongs survival for more than $6 \mathrm{hr}$ but less than $24 \mathrm{hr}$ following ligation of the descending coronary artery. Fearon (1967) has also shown prolonged survival in anaesthetized dogs in whom ischaemia, cardiac arrhythmias and death were produced by the injection of microspheres at the aortic root (Table 6).

Since the size of a myocardial infarct has a marked influence on survival, studies on the effect of $\beta$-antagonists on infarct size are relevant. Reimer, Rasmussen and Jennings (1973) have shown that propranolol $(5.0 \mathrm{mg} / \mathrm{kg}$ i.v. $)$ will reduce the amount of necrosis of papillary muscle in the anaesthetized dog following experimental infarction by approximately $40 \%$. Paradoxically, in their study propranolol did not increase survival even though it very significantly reduced the area of necrosis. Maroko and Braunwald (1973) have shown that propranolol will reduce the area of infarction following ligation of coronary artery in the anaesthetized dog. In these experiments the area of necrosis was measured by serial determinations of ST segment elevation as well as serum and tissue creatinine phosphokinase levels. Clearly the relevance of these studies to the effects of $\beta$-antagonists on morbidity and mortality in man will depend on the outcome of prospective studies in matched patients.

\section{Studies in man}

\section{Acute myocardial infarction}

Based on the large amount of experimental work there were good reasons to evaluate the effect of

TABLE 6. $\beta$-Blockade and mortality in experimental infarction (anaesthetized dogs)

\begin{tabular}{lccc}
\hline \multicolumn{1}{c}{ Author } & Drug & Dose $(\mathrm{mg} / \mathrm{kg})$ & Mortality \\
\hline Pentecost (1966) & Propranolol & Saline & $85 \%$ \\
& & 0.08 & $14 \%$ \\
& & 0.2 & $50 \%$ \\
Fearon (1967) & Propranolol & Control & $31.5 \%$ (ventricular \\
& & $0.25 \mathrm{mg}$ & fibrillation) \\
& & & $0.0 \%$ \\
Harris et al. (1971) & Practolol & Control & $80 \%$ \\
& & 3.0 & $0 \%$ \\
Kaumann and Aramendia 1968) & Sotalol & Control & $<6 \mathrm{hr}$ \\
& & 0.5 & $<6 \mathrm{hr}$ survival \\
& & 10.0 & $>6 \mathrm{hr},<24 \mathrm{hr}$ \\
\hline
\end{tabular}




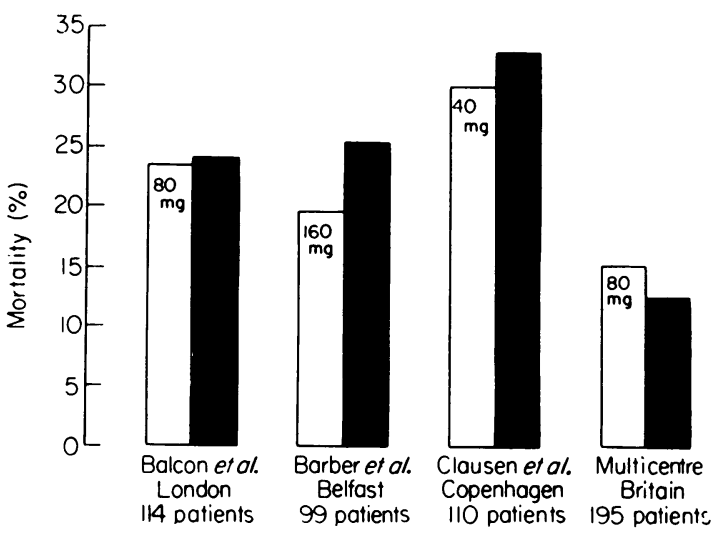

FIG. 1. Comparison of mortality rates following acute myocardial infarction between propranolol and control series. None of the differences is statistically significant (from Sowton (1968), by kind permission of the Editor, Progress in Cardiovascular Diseases). $\square$, Propranolol; , control.

$\beta$-antagonists administered during the acute phase of myocardial infarction. The initial study carried out by Snow (1965) suggested that propranolol $(20 \mathrm{mg}$, 6-hourly) administered to patients within $6 \mathrm{hr}$ of an acute myocardial infarction would reduce mortality from $35 \%$ to $16 \%$. Further studies by Snow (1965) involving a total of 107 patients confirmed his preliminary findings in that the mortality was reduced from $29 \%$ in the control group to $13 \%$ in the treated group. These exciting results could not be confirmed in a series of large, well designed prospective studies (Fig. 1). In summary, these studies showed that propranolol in a dose of between 40 and $120 \mathrm{mg} /$ day given within $12 \mathrm{hr}$ of an acute myocardial infarction did not affect mortality rate. Similar studies (Snow, 1966) using the $\beta$-antagonist oxprenolol also failed to show any reduction in mortality in acute myocardial infarction.

Recently, Barber et al. (1975) have reviewed their experience of the administration of practolol in acute myocardial infarction. Their study was a randomized double-blind prospective study involving 500 consecutive patients admitted to the coronary care unit with suspected acute myocardial infarction. Patients were given either $300 \mathrm{mg}$ of practolol 12-hourly or an identical placebo. Therapy was commenced as soon as the patient was seen and treatment with tablets was maintained for 2 years. Two hundred and ninety-eight of the patients had a proved myocardial infarction as determined by clinical history, electrocardicgraphic changes and serum enzyme elevation. The time between the onset of symptoms and the administration of intensive coronary care varied widely but $50 \%$ of the patients were seen within $31 \mathrm{hr}$. One hundred and fifty-one patients received practolol and the remainder placebo. Mortality after 3 months on practolol was $15 \%$ compared with $17 \%$ on placebo whilst at 2 years the figures were $27 \%$ and $31 \%$. Thus, there was no change in mortality even though the $\beta$-antagonist was administered very early in the course of the myocardial infarction.

The effect of practolol in patients with a high initial heart rate was also analysed. Fifty-three patients had an initial heart rate of $\geqslant 100$ beats/min and twenty-three received practolol whilst thirty received placebo. The two groups in this sub-set were matched for sex, age, prognostic index and time to admission. After $24 \mathrm{hr}$ all of the practolol-treated patients were alive whilst four in the placebo group died. At the time of discharge from hospital, $23 \%$ (seven patients) in the placebo group had died whilst $4 \%$ (one patient) in the practolol treated group had died. The difference in mortality between the two groups remains statistically significant for the first 12 months but not at 24 months.

\section{Secondary prevention studies}

It is clear that the routine administration of $\beta$-antagonists during the acute phase myocardial infarction has not been shown to influence the outcome with the possible exception of the study bs Barber et al. (1975) which suggests that patients witb a heart rate of $>100$ beats/min during the acute phase may be benefited by $\beta$-receptor blockade. major objection to the type of study where $\beta$ antagonist is given only after the patient has developed symptoms is that it is too late in the evolution of the condition to expect the agents to be of value since the patients only present once they have symptoms. Studies have, therefore, been carried out to determine the effect of chronic administration of $\beta$-antagonists to patients before the development of myocardial infarction. The population selected for study would have to have a high incidence of myocardial infarction for the experiment to be feasible. One approach to this problem is that reported by Fox et al. (1975) who studied the incidence of myocardial infarction in patients admitted to a coronary care unit because of attacks of prolonged chest pain. Ninety of these patients were receiving $\beta$-antagonists for at least 1 month before admission and they were matched with ninety control patients who had not been receiving $\beta$-antagonists during this time. It should be noted that the $\beta$-antagonist was abruptly withdrawn on admission to the coronary care unit, so presumably $\beta$-blockade was present for, at most, the first $24 \mathrm{hr}$ following admission.

Transmural myocardial infarction was confirmed in thirty patients receiving $\beta$-antagonists and in sixty-two patients not receiving them. In contrast, forty patients on $\beta$-antagonists were considered to 
TABLE 7. Effect of prophylactic administration of $\beta$-antagonists on morbidity and mortality in myocardial infarction

\begin{tabular}{|c|c|c|c|c|c|}
\hline Author & Drug & $\begin{array}{l}\text { No. of } \\
\text { patients }\end{array}$ & Design & Duration & Morbidity and mortality \\
\hline Reynolds and Whitlock (1972) & $\begin{array}{l}\text { Alprenolol } \\
400 \mathrm{mg}\end{array}$ & 78 & $\begin{array}{c}\text { Blind } \\
\text { prospective }\end{array}$ & 1 year & No difference \\
\hline Barber et al. (1975) & $\begin{array}{l}\text { Practolol } \\
600 \mathrm{mg}\end{array}$ & 298 & Blind & 2 years & $\begin{array}{l}\text { No difference except in } \\
\text { high heart rate group }\end{array}$ \\
\hline Ahlmark et al. (1974) & $\begin{array}{l}\text { Alprenolol } \\
400 \mathrm{mg}\end{array}$ & $\begin{array}{l}162 \\
69 \text { treated } \\
95 \text { control }\end{array}$ & Open & 2 years & $\begin{array}{l}\text { Sudden death } \\
\text { treated : control }=1: 9 \\
\text { Re-infarction }=4: 15\end{array}$ \\
\hline Wilhelmsson et al. (1975) & $\begin{array}{l}\text { Alprenolol } \\
400 \mathrm{mg}\end{array}$ & 230 & $\underset{\text { Prospective }}{\text { Blind }} \cdots$ & 2 years & $\begin{array}{l}\text { Sudden death }=3: 11 \\
\text { Re-infarction }=16: 18\end{array}$ \\
\hline Stephen (1966) & $\begin{array}{l}\text { Practolol } \\
400 \mathrm{mg}\end{array}$ & $\begin{array}{c}3050 \\
\text { approx. }\end{array}$ & $\begin{array}{c}\text { Blind } \\
\text { Prospective }\end{array}$ & $1-3$ years & $\begin{array}{l}\text { Significant reduction in } \\
\text { patients with anterior } \\
\text { infarction }\end{array}$ \\
\hline
\end{tabular}

have coronary insufficiency whilst this was present in only fourteen controls. Both these differences are statistically significant.

It is difficult to know what firm conclusions can be drawn from such a study. The practical implication would seem to be that the development of acute coronary insufficiency whilst receiving a $\beta$-antagonist is less likely to lead to myocardial cell death and thus preserves functioning myocardium. There are several difficulties in accepting such a conclusion. The experimental design meets few of the criteria given previously, in particular the retrospective nature of the study gives cause for concern. For example, it is possible that many of the patients on $\beta$-antagonists died before admission and that a highly selected group is being observed. An analysis of mortality rates in the two groups amongst those who had had previous infarction might have been revealing. Certainly it would be desirable to know the subsequent long-term outcome of this study.

An alternative approach has been to study the effects of $\beta$-antagonists in patients who have survived the first few weeks of an acute myocardial infarction. Reynolds and Whitlock (1972) have reported on their experience of a double-blind prospective study in which the $\beta$-antagonist alprenolol was administered in a dose of $100 \mathrm{mg}$ four times daily or a placebo to a total of eighty-seven patients from the time of admission to the coronary care unit until 12 months had elapsed. Treatment was administered in random order and any patient who subsequently was shown not to have an acute myoacrdial infarction was withdrawn from the study. Patients were also excluded if there were contraindications to $\beta$-blockade. The contra-indications were a systolic blood pressure of less than $90 \mathrm{mmHg}$, pulmonary oedema, sinus bradycardia of less than 50 beats/min and bronchial asthma. Of 119 patients initially admitted to the study, nine died, ten were withdrawn because of cardiovascular complications, and thirteen were excluded because they did not meet the diagnostic criteria. A total of eighty-seven patients remained for study for the following 12 months. Nine of the eighty-seven patients dropped out of the study leaving a total of seventy-eight for the final analysis. During the year of follow-up six patients died, three whilst receiving alprenolol and three on placebo. All deaths were due to an acute coronary event. Physiological studies were carried out at intervals on thirty patients during the year, of whom fifteen were receiving alprenolol. For the sake of the protocol, alprenolol had to be withdrawn abruptly at least $18 \mathrm{hr}$ before the studies, yet this does not seem adversely to have affected their clinical condition.

There have been two other studies in which the effects of alprenolol on re-infarction and sudden death has been studied in patients who have recovered from a previous myocardial infarction. In the study by Ahlmark, Saetre and Korsgrain (1974) 393 patients, who were admitted to hospital with suspected myocardial infarction, were randomly allocated to either a treatment group comprising alprenolol $100 \mathrm{mg}$ four times daily or no $\beta$-antagonist. Of the initial 393 patients who were randomized to treatment or no treatment, 231 were withdrawn for various reasons, i.e., (a) incorrect diagnosis (158 patients), (b) hospital death (thirty-five patients), (c) contra-indication to $\beta$-antagonists (twenty-one patients), (d) outside hospital catchment area (seventeen patients). Of the remaining 162 patients who continued in the study, ninety-three were in the control group and sixty-nine were allocated to treatment with alprenolol. At the end of 2 years, analysis of the data showed that four patients in the alprenolol-treated group had a recurrence of myocardial infarction compared with fifteen in the control group. This difference is statistically significant 
$(P>0.05)$. Furthermore, there was one sudden death in the alprenolol-treated group compared with nine in the control group, which is a statistically significant difference at the $5 \%$ level.

Whilst the results from this study suggest that the chronic administration of a $\beta$-antagonist will reduce the incidence of re-infarction and also sudden death, the study can be criticized on several grounds. Firstly, incorrect randomization procedures were used in that the subjects were randomized before determining their eligibility for the study. Despite the authors' disclaimer, this method of randomization will lead to bias in patient selection. Further evidence of bias could be found in the imbalance in numbers between the control group (ninety-three patients) and the treated group (sixtynine patients). Furthermore, the study was an open one and co-intervention was not practised in that the control group did not receive any placebo therapy.

Wilhelmsson et al. (1974) reported the results of a study in which alprenolol $400 \mathrm{mg}$ daily in two divided doses was compared with placebo treatment in $\mathbf{2 3 0}$ patients who survived acute myocardial infarction and were discharged from hospital. The patient population comprised subjects in the age group 57-67 years of age, and of the initial 274 patients eightyseven were female. Forty-four patients were excluded from the initial group because they exhibited contra-indications to $\beta$-blockade. The patients were classified into four sub-groups based on clinical, electrocardiographic and biochemical evidence of increasing myocardial damage.

The effect of alprenolol was assessed by two endpoints, either non-fatal re-infarction or death. In the alprenolol-treated group there were three sudden deaths, whilst in the placebo group there were eleven sudden deaths. The total number of deaths were seven in the alprenolol-treated group compared with fourteen in the placebo group. The difference in the incidence of sudden death between the alprenolol-treated group and the placebo-treated group was significant at the $5 \%$ level. There was no difference between the two treatment groups in respect to nonfatal re-infarctions, there being eighteen in the

TABLE 8. Summary of effects of $\beta$-antagonists on morbidity and mortality in ischaemic heart disease

\footnotetext{
Angina pectoris

May reduce death rate

Controlled studies required

Myocardial infarction

Acute phase: no reduction

Secondary prevention: mortality reduced in two controlled studies

Sudden death

Secondary prevention: reduced in one study

Primary prevention: not available
}

placebo-treated group and sixteen in the alprenolol- $\frac{3}{3}$ treated group.

This is a well designed study in that there are $c$. adequate controls, clearly defined end-points, co- $\overrightarrow{\vec{F}}$ intervention is practised, the study is double-blind $\frac{\text { f }}{\square}$ and the numbers are adequate. It would seem reason- $\frac{}{2} \bar{C}$ able to conclude from such a study that the routine $\frac{\bar{\sigma}}{\overline{0}}$ administration of the $\beta$-antagonist, alprenolol, in $\frac{\sigma}{\sigma}$ patients who have survived the hospital phase of $\varrho$ acute myocardial infarction will reduce the incidence $\%$ of sudden death though not of re-infarction. The $\overrightarrow{0}$ conclusions of this study, therefore, do not support the conclusions of the study by Ahlmark et al. (1974) $\vec{\omega}$ in which a reduction of re-infarction as well assudden death is claimed. It is not immediately obvious why these results are in conflict with those previously reported by Reynolds and Whitlock N (1972) but a possible explanation is that the latter $\stackrel{9}{\rightarrow}$ study involved too few patients and was of insufficient duration to show a difference. Furthermore, $\mathcal{O}$ that study was not designed solely to examine the effects of $\beta$-antagonists on morbidity and mortality.

The study by Barber et al. (1975) of the effects of $\vec{\nabla}$ practolol in acute myocardial infarction extended $\Phi$ over 2 years and information is available on a total ${ }_{3}^{\Phi}$ of 484 cases of whom 186 had prolonged cardisc pain but no evidence of myocardial infarction. During the 2-year follow-up period, there were $\overrightarrow{0}$ forty-four episodes of recurrent acute myocardiegl oे infarction or sudden death. Seventeen of the episodes occurred in the practolol-treated group and twenty-seven in the placebo-treated group. This difference is not statistically significant. The overall mortality in the two weeks following the recurrence $\frac{}{\Phi}$

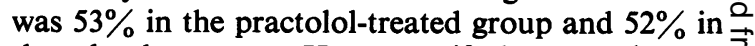
the placebo group. However, if these results are stratified with respect to time of death following recurrence of the coronary episode, it was found that $19 \%$ of the deaths occurred within the first $24 \mathrm{hr}$ in the placebo-treated group but only $6 \%$ in the practo- $\frac{0}{3}$ lol-treated group. This trend, although not statistically significant, would confirm the findings of 3 Wilhelmsson et al. (1974) in respect of the incidence 8 of sudden death in patients receiving a $\beta$-antagonist. As the authors remark in their discussion, at least 0 2,000 patients with acute myocardial infarction studied over 2 years would be necessary to confirm statistically the trend that they have observed.

An appropriate trial addressed to this problem has $\mathcal{O}$ been carried out over the last 2 years in the U.K. N (Green, 1975). The objectives of the large multi- N centre U.K. trial was to determine whether the long- $\sigma$ term administration of practolol with patients recovering from myocardial infarction would reduce the subsequent incidence of mortality. Patients of $\stackrel{\mathscr{\Phi}}{+}$ not more than 70 years of age were admitted to the study who had suffered an acute myocardial infarc- 0 
tion based on clinical, biochemical, and electrocardiographic changes. They were placed on either placebo or practolol $200 \mathrm{mg}$ twice daily. Treatment was initiated between the seventh and twenty-eighth day following the diagnosis of myocardial infarction. The patients were withdrawn from the study on death in hospital, extension of infarction, anginal pain uncontrolled by trinitrin, bradycardia, or adverse reactions. Patient compliance was tested by random measurement of plasma levels of practolol. Particular attention was paid to adequate follow-up of defaulters.

A total of 3,038 patients was studied for between 1 and 3 years. The practolol-treated group showed a significant reduction in overall mortality in that there were forty-seven deaths in the treated group and seventy-three deaths in the placebo group $(P>0.02)$. In addition, there was a significant difference $(P>0.01)$ in all events (i.e. deaths plus non-fatal infarctions) between the placebo and practolol groups. The number of sudden deaths was also significantly less in the practolol-treated group. An unexpected finding in this study was the highly significant reduction in mortality in those patients receiving practolol who sustained septal or lateral infarction (22 v. 48; $P>0.01)$. There was no difference in mortality in patients with inferior infarction (25v. 25).

This large study fulfils the majority of the design criteria to enable valid conclusions to be drawn. It shows that the prolonged administration of practolol to patients surviving the acute phase of myocardial infarction reduces the death rate when the original infarct is sited anteriorly.

\section{Conclusions (see Table 8)}

The effect of $\beta$-receptor antagonists on morbidity and mortality in ischaemic heart disease has been the subject of intensive study over the past 5 years. In the case of angina pectoris no final conclusion can be drawn at the present time. The uncontrolled studies of Amsterdam et al. (1968) in the U.S.A. and Lambert in the U.K. (1972) suggest that mortality may be reduced in these conditions by the prophylactic administration of $\beta$-antagonists. The most that can be concluded from these studies at the present time is that the administration of these drugs does not increase mortality in this condition. For the future, studies are required in patients in whom the anginal syndrome has been more accurately characterized. It would be particularly important to know the degree and extent of coronary vessel disease in the patients selected for study since prognosis is so markedly affected by the degree of vessel involvement. Further studies are required to determine the role of $\beta$-antagonists in both the stable and unstable forms of angina pectoris. These studies should be designed so that ethical considerations do not irrevocably compromise the requirements of an adequate experimental design.

Extensive studies of the effect of $\beta$-antagonists administered during the acute phase of myocardial infarction indicate that they do not reduce either morbidity or mortality and that they may increase morbidity in certain situations. The secondary prevention studies by Wilhelmsson show that there is a reduction in the mortality but not re-infarction rate if alprenolol is taken for 12 months or longer following recovery from an initial myocardial infarction. The studies of Barber et al. (1976) suggest that patients with a high initial heart rate benefit from practolol therapy. The multi-centre study shows that patients with anterior myocardial infarction are benefited by the prophylactic adminstration of $\beta$-antagonists. These encouraging results with practolol pose the question as to the validity of applying these data to other $\beta$-antagonists now that chronic practolol administration may be hazardous. Are the beneficial effects due to practolol itself or are they due solely to antagonism of $\beta$-receptors? If it is due to $\beta$-antagonism, is the cardio-selective nature of practolol an important factor in the improved prognosis?

In a different context, large trials of the effect of anti-platelet drugs on the incidence of morbidity and mortality in ischaemic heart disease are currently in an advanced state of planning. It would be worth considering adding a propranolol-treated group to such studies in order to determine the relative contribution of $\beta$-antagonists and anti-platelet drugs to survival. Another relatively unexplored area is the effect of $\beta$-antagonists on morbidity and mortality in hypertension. Now that the hypotensive action of $\beta$-antagonists is proved, there are several reasons why such a prospective study should be undertaken. For the present, the practising physician should adopt a cautious attitude to the routine prophylactic administration of $\beta$-antagonists in the everyday management of patients with coronary artery disease. The sobering story of the role of anticoagulant therapy in acute myocardial infarction is too recent to encourage an over-enthusiastic approach to the use of $\beta$-antagonists to reduce mortality due to ischaemic heart disease, until all the available data are published.

\section{References}

Ahlmark, G., Saetre, H. \& Korsgrain, M. (1974) Reduction of sudden deaths after myocardial infarction. Lancet, ii, 1563.

Alderman, E.L., Coltart, J., Wettach, G.E. \& Harrison, D.C. (1974) Coronary artery syndromes after sudden propranolol withdrawal. Annals of Internal Medicine, 81, 625. 
Amsterdam, E.A., Wolfson, S. \& Gorlin, R. (1968) Effect of therapy on survival in angina pectoris. Annals of Internal Medicine, 68, 1151.

Aronow, W.S. (1969) Propranolol combined with isosorbitinitrate versus placebo in angina pectoris. New England Journal of Medicine, $280,847$.

Aronow, W.S. \& Stemmer, E.A. (1974) By-pass graft surgery versus medical therapy of angina pectoris. American Journal of Cardiology, 33, 415.

Balcon, R., JewIT, D.E., Davies, J.P.H. \& ORAM, S. (1966) Propranolol in myocardial infarction. Lancet, ii, 1317.

Barber, J.M., Boyle, D.McC., Chaturvedi, N.C., Singh N. \& WALSH, M.J. (1975) Practolol in acute myocardial infarction. Acta medica scandinavica, 587 (Suppl.), 213.

BARReTt, A.M. \& Fitzgerald, J.D. (1968) What is a betablocker? American Heart Journal, 76, 712.

Bendtzen, K. \& Soborg, M. (1975) Sclerosing peritonitis and practolol. Lancet, i, 629.

BLACK, J.W. (1967) The predictive value of animal tests in relation to drugs affecting the cardiovascular system in man. In: Drug Responses in Man (Ed. by G. Wolstenholme and R. Porter), p. 121. Churchill, London.

Bocage, A.J. \& HARris, A.S. (1971) Preventive effect of beta adrenergic blockade with practolol on early ventricular arrhythmias after coronary occlusion. Circulation, 43/44 (Suppl. 2), 142, Abst. 529.

Davies, R.O., Mizgala, H.F., Tinmouth, A.C., Waters, D.D. \& Counsell, J. (1975) Prospective controlled trial of long term propranolol on acute coronary events in patients with unstable coronary artery disease. Clinical Pharmacology and Therapeutics, 17, 232.

DE QuatrRo, V. (1972) Raised plasma catecholamines in some patients with hypertension. Lancet, i, 806.

Ebert, P.A., Allgood, R.J. \& Sabiston, D.C. (1968) Antiarrhythmic effect of cardiac denervation. Annals of Surgery, $168,723$.

EDITORIAL (1975) Side effects of practolol. Lancet, i, 289.

FEARON, R.E. (1967) Propranolol in the prevention of ventricular fibrillation due to experimental coronary artery occlusion. American Journal of Cardiology, 20, 222.

FeLIX, R.H., IVE, F.A. \& DAHL, M.G.C. (1975) Skin reactions to beta blockers (practolol, propranolol). British Medical Journal, 1, 626.

FitzGerald, J.D. (1972) The role of beta adrenergic blockade in acute myocardial ischaemia. In: The Effect of Ischaemia on Myocardial Function (Ed. by M. F. Oliver, D. G. Julian and K. W. Donald). Churchill-Livingstone, London.

Fox, K.M., Chopra, M.P., Portal, R.W. \& Aber, C.P. (1975) Long term beta blockade: possible protection from myocardial infarction. British Medical Journal, 1, 117.

Gazes, P.C., Richardson, J.A. \& Woods, E.F. (1959) Plasma catecholamine concentrations in myocardial infarction and angina pectoris. Circulation, 19, 657.

Gifford, R.H. \& FeinsteIn, A.R. (1969) A critique of methodology in studies of anti-coagulant therapy for acute myocardial infarction. New England Journal of Medicine, $280,351$.

Griffiths, J. \& LeUNG, F. (1971) The sequential estimation of plasma catecholamines and whole blood histamine in myocardial infarction. American Heart Journal, 82, 171.

Harris, A.S., Otero, H. \& Bocage, A.J. (1971) The induction of arrhythmias by sympathetic activity before and after occlusion of a coronary artery in the canine heart. Journal of Electrocardiology, 4, 34.

Hope, R.R., Williams, D.O., El-Sherif, N., Lazzara, R. \& ScherLAG, B.J. (1974) The efficacy of anti-arrhythmic agents during acute myocardial ischaemia and the role of heart rate. Circulation, 50, 507.

Jequier, E. \& Perret, C. (1970) Urinary excretion of catecholamines and their main metabolites after myocardial

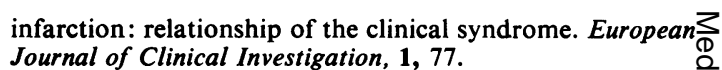

Kahn, M.I., Hamilton, J.T. \& Manning, G.W. (1972)C Protective effect of beta adrenoceptive blockade in experimental coronary occlusion in conscious dogs. American Journal of Cardiology, 30, 832.

KahN, M.I., Hamilton, J.T. \& ManNing, G.W. (1973)을 Early arrhythmias following experimental coronary occlusion in conscious dogs and their modification by beta $\frac{\bar{T}}{2}$ adrenoceptor blocking drugs. American Heart Journal, 86, 347.

KaumanN, A.J. \& Aramendia, P. (1968) Prevention of ventricular fibrillation induced by coronary ligation. $\vec{\circ}$ Journal of Pharmacology and Experimental Therapeutics, 164, 326.

LAMBERT, D.M.D. (1972) Beta blockers and life expectancy $\vec{\omega}$ in ischaemic heart disease. Lancet, i, 793.

LAMBERT, D.M.D. (1974) Hypertension and myocardial in farction. (Correspondence) British Medical Journal, 3, 6853

Maroko, P.R. \& Braunwald, E. (1973) Modification of "'s myocardial infarction size after coronary occlusion. Annals of Internal Medicine, 79, 720.

Mizgala, H.F. \& Counsell, J. (1974) Acute coronary syn $-\vec{\nabla}$ dromes following abrupt cessation of oral propranolol $\forall$ therapy. Circulation, 49/50 (Suppl. 3), 33.

Mizgala, H.F., Tinmouth, A.L., Walters, D.D., Counsell, 음 J. \& DAvies, R.O. (1974) Prospective control trial of long term propranolol on acute coronary events in patients with unstable coronary artery disease. Circulation, $50{ }_{\mathbb{\Phi}}$ (Suppl. 3), 235, Abstract 933.

MORRIS, J.J., WOHLGEMUTH, S., JACKSON, D., WhELAN, R.E. $\stackrel{\Phi}{3}$ \& McInTosh, H.D. (1967) Quinidine, propranolol a两 polarizing solution in the treatment of experimental myबcardial infarction. Clinical Research, 15, 57.

Nellen, M. (1973) Withdrawal of propranolol and myacardial infarction. Lancet, i, 558.

Olson, H.G., Miller, R.R., Amsterdam, E.A., Wood, Meq, $^{\circ}$ Brocchini, R. \& MASON, D.T. (1975) Acute exacerbation of myocardial ischaemic symptoms and death following sudden cessation of large doses of propranolol in coronary $\bar{\partial}$ artery disease. Clinical Research, 23, 83a.

Pentecost, B.L. (1966) Beta adrenergic blockade in experi- $\stackrel{\circ}{\Phi}$ mental myocardial infarction. American Heart Journal, 72, 790.

RAAB, W. (1962) The sympathogenic biochemical trigger 3 mechanism of angina pectoris. American Journal of $\vec{\partial}$ Cardiology, 7, 576.

Raftery, E.P. \& Denman, A.M. (1973) Systemic lupus erythematosus syndrome induced by practolol. British $\bar{\partial}$ Medical Journal, 2, 452.

Reimer, K.A., Rasmussen, M.M. \& Jennings, R.B. (1973) Reduction by propranolol of myocardial necrosis following temporary coronary artery occlusion in dogs. Circulation Research, 33, 353.

ReYNoldS, J.L. \& WhitLock, R.M.L. (1972) Effects of a beta adrenergic receptor blocker in myocardial infarction treated for one year from onset. British Heart Journal, 34, 252.

SchaAl, S.F., Wallace, A.G. \& Sealy, W.C. (1969) Protective influence of cardiac denervation against arrhythmias $\mathrm{N}$ of myocardial infarction. Cardiovascular Research, 3, 241.

SLOME, R. (1973) Withdrawal of propranolol and myocardial 0 infarction. Lancet, i, 156.

SNow, P.J.D. (1965) Effect of propranolol in myocardial in- $\sigma$ farction. Lancet, ii, 551.

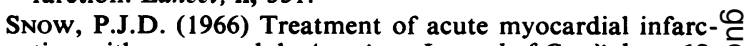
tion with propranolol. American Journal of Cardiology, 18,

Sowton, E. (1968) Beta adrenergic blockade in cardiac in farction. Progress in Cardiovascular Diseases, 10, 561. 
Stephen, S.A. (1966) Propranolol in acute myocardial infarction: a multicentre trial. Lancet, ii, 1435.

Valori, C., Thomas, M. \& Shillingford, J. (1967) Free noradrenaline and adrenaline excretion in relation to clinical syndromes following myocardial infarction. American Journal of Cardiology, 20, 605.

WARREN, S.G., BreWER, D.L. \& Orgain, E.S. (1974) Propranolol in the long term treatment of angina pectoris. American Journal of Cardiology, 33, 176.
Wilhelmsson, C., Wilhelmsson, L., Vedin, J.A., Tibblin, G. \& WERKo, L. (1974) Reduction of sudden death after myocardial infarction by treatment with alprenolol. Lancet, ii, 1157.

Wilson, D.F., Watson, O.F., Peel, J.S. \& Turner, A.S. (1969) Trasicor in angina pectoris: a double-blind trial. British Medical Journal, 2, 155. 